\title{
Inverted Papilloma of the Urinary Bladder Case Report
}

\author{
Nasuhi E. Aydin, M.D., Azam Demirel, M.D. \\ Erzurum, Turkey
}

DOI: http://dx.doi.org/10.5915/24-1-15481

\begin{abstract}
A case of inverted papilloma of the urinary bladder, a relatively uncommon tumor that caused gross painless hematuria of long duration in a 41 year old male patient, is presented. The patient was cured after local resection and is free of disease after a 20 month follow-up.
\end{abstract}

Key words: Urothelial tumors, inverted papilloma.

Inverted papillomas are rare tumors of the lower urinary tract that show an endophytic growth pattern. These lesions may mimic invasive carcinomas both clinically and pathologically. ${ }^{1-3}$ We report a case showing trabecular pattern of growth as delineated by Kunze et al. ${ }^{3}$ which caused gross hematuria of long duration.

\section{Case report}

A 41 year old male patient, working as an agricultural engineer at a sugar refinery presented with gross painless hematuria. His complaints began four years ago but he had been free of urinary problems for the last two years, until his hematuria had recently recurred.

Physical examination showed a grade 11 varicocele on the left side. $\mathrm{CBC}$, blood electrolytes, coagulation tests, chest X-ray and EKG were within normal limits. An Intravenous Pyelogram (IVP) was normal,

From the Departments of Anatomic Pathology and Urologic Surgery

Ataturk University School of Medicine

Research Hospital, Erzurum, Turkey

Reprint Requests: Nasuhi E. Aydin, M.D.

Associate Professor of Pathology

Department of Anatomic Pathology

Ataturk University School of Medicine

Erzurum, Turkey, 25240. but a cystoscopy revealed a $1.5 \times 1 \mathrm{~cm}$ smooth, broad based lesion at the base of the bladder neck at the 11 o'clock position. A biopsy was reported as epithelial proliferation consistent with inverted papilloma of the bladder.

The patient was given a trial of urinary antiseptics and spasmolytics. Because of continuation of his hematuria, full resection of the lesion was performed endoscopically four months later.

The specimen received was tan tissue fragments measuring $1.5 \mathrm{~cm}$ in aggregate. The microscopic examination revealed the same appearance seen in the former biopsy. The surface showed a focally eroded, attenuated transitional epithelium. An endophytic growth of uniform cuboidal cells devoid of mitotic activity was seen. The cells were arranged in irregularly ramifying, anastomosing cords, columns or sheets. (Figure 1)

Peripheral palisading of the cells was discernible in most areas. Foci of small cystic spaces within the solid structures lined by flattened cells and filled with variable amounts of homogeneous, eosinophilic, weakly PAS-positive material were seen. (Figure 2)

The intervening stroma was hypocellular and edematous. There was neither noticeable inflammation nor changes consistent with cystitis glandularis in the nearby bladder tissue.

Upon removal of the lesion and during his followup for $\mathbf{2 0}$ months the patient has remained free of local recurrence. 


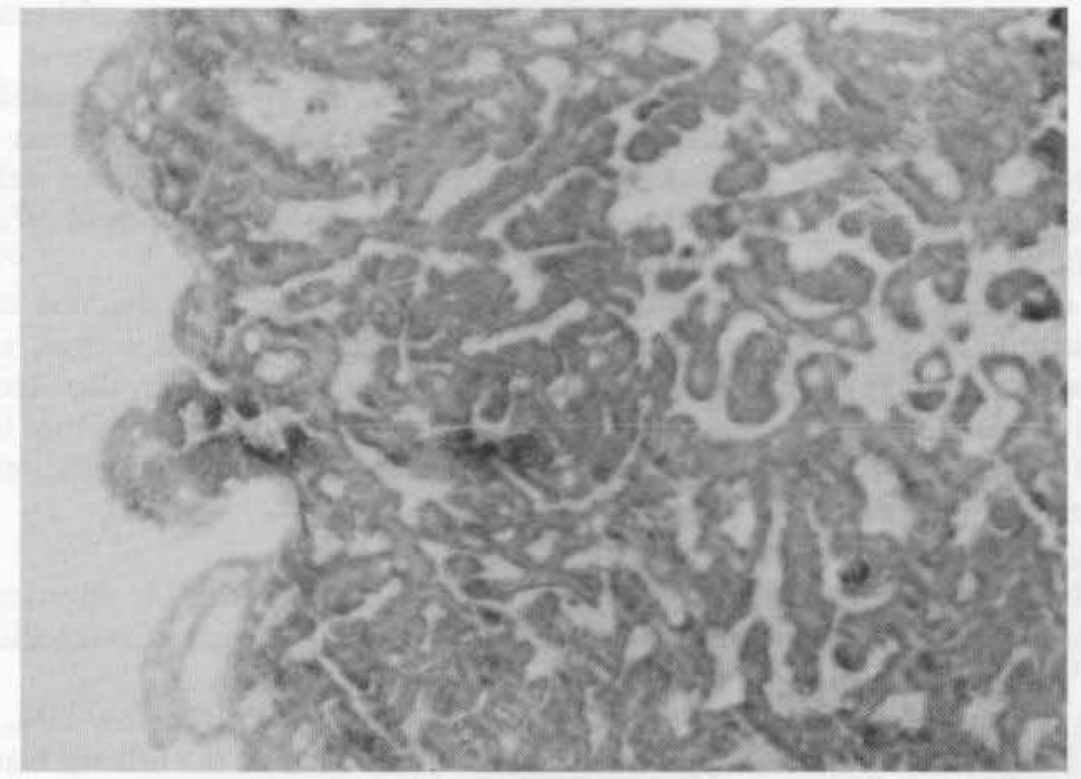

Figure 1. Low power view of the lesion showing trabecular pattern of growth (Hematoxylin and eosin).

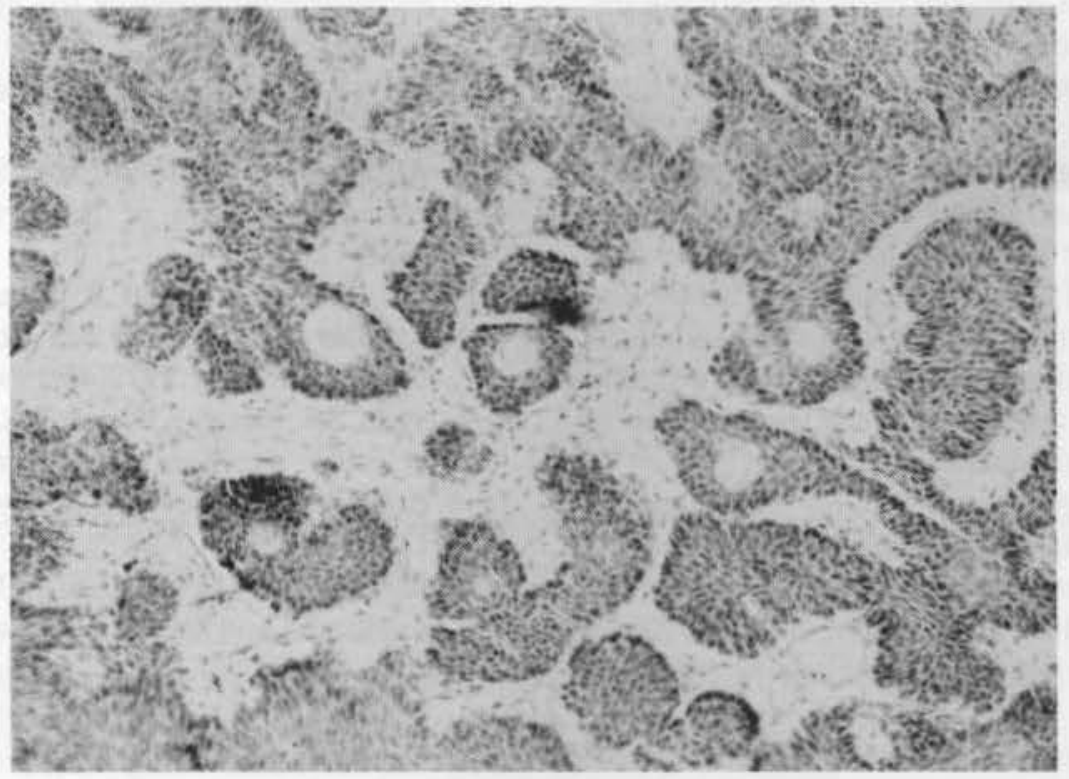

Figure 2. Intermediate power view, showing the edematous stroma and cystic spaces within the neoplastic growth (Hematoxylin and eosin). 


\section{Discussion}

Inverted papillomas of the lower urinary tract are well defined lesions that must be clearly segregated from other lesions, the main differential diagnosis being transitional cell carcinoma. ${ }^{1-3}$

Even though these lesions were described as early as 1927 , the currently accepted designation was coined in 1963 by Potts and Hirst. ${ }^{4}$ The actual incidence has not been established but it can be speculated that they are more frequent than commonly assumed. In 1974 there were only 26 cases on record, however the number approached 200 recently. ${ }^{2-5}$

The most common locations in order of frequency are the bladder neck, trigone, anterior, posterior and lateral walls and base of the bladder, prostatic urethra. Rare cases involving the renal pelvis and ureter are reported., 3,5

The cases show a great male preponderance with most of the patients being in the sixth decade, presenting with symptoms of hematuria and/or obstruction. ${ }^{1-3,6}$

The gross features mainly show a gray to white lesion with smooth glistening surface, firm in consistency, usually less than $3 \mathrm{cms}$ and a pedunculated or sessile base. Microscopically the lesion is typically covered by transitional epithelium which may be normal or atrophic. The epithelial cords beneath the surface are composed of urothelial cells showing compact arrangement and small amounts of cytoplasm. There is little if any mitotic activity or atypia..$^{2,3,6}$

Kunze et $\mathrm{al}^{3}$ have described two histological variants. A glandular variety showing pseudo glandular and glandular structures with round and oval islands of urothelial cells. This pattern is believed to arise from pre-existing cystitis cystica glandularis. The second variety shows a trabecular pattern similar to the one seen in our case. These lesions seem to arise from urothelial basal cells.

Our case fulfills the criteria laid for the trabecular type of inverted papillomas. Both the clinical and pathological features are in accord with the present knowledge about these lesions. The patient's age is somewhat younger than the usual age of presenta- tion. Following an uneventful recovery the patient is found to be free of disease after 20 months. However, in view of the recently published cases stressing either the association of concurrent or potential risk of transitional cell carcinomas with these lesions, a longer period of careful follow-up is mandatory..$^{7-9}$

Recent reports also describe cases located in the upper urinary tract. Moreover, a case of malignant inverted papilloma has also been clearly verified. This gives very clear proof that these lesions are indeed neoplastic and must be carefully evaluated..$^{s-10}$

\section{References}

1. Caro DJ, Tessler A: Inverted papilloma of the bladder, a distinct urological lesion. Cancer 1978;42:708-13.

2. DeMeester LJ, Farrow GM, Utz DC: Inverted papillomas of the urinary bladder. Cancer 1975; 36:505-13.

3. Kunze E, Schauer A, Schmitt M: Histology and histogenesis of two different types of inverted urothelial papillomas. Cancer; 1983;51:348-58.

4. Potts IF, Hirst E: Inverted papilloma of the bladder. J Urol 1963;90:175-9.

5. Kyriakos M, Royce RK: Multiple simultaneous inverted papillomas of the urinary tract. Cancer 1989;63:368-80.

6. Palvio DHB: Inverted papillomas of the urinary tract. Scand J Urol Nephrol 1985;19:299-302.

7. Anderstrom C, Johansson S, Pettersson S: Inverted papilloma of the urinary tract. J Urol $1982 ; 127: 1132-4$.

8. Lazarevic B, Garrett R: Inverted papilloma and papillary transitional cell carcinoma of urinary bladder. Cancer 1978;42:1904-11.

9. Stein BS, Rosen S, Kendall R: The association of inverted papilloma and transitional cell carcinoma of the urothelium. J Urol 1983; 131:751-2.

10. Altaffer LF(III), et al.: Malignant inverted papilloma and carcinoma in situ of the bladder. $J$ Urol 1982;128:816-8. 